\title{
MEGAFAUNA DO PLEISTOCENO FINAL DE MATINA, BAHIA, BRASIL: SISTEMÁTICA, CRONOLOGIA E PALEOECOLOGIA
}

\author{
LEONARDO SOUZA LOBO \\ Departamento de Biologia Animal, Museu de Zoologia João Moojen, UFV, Vila Gianetti, casa n $32,36570-000$, \\ Viçosa, MG, Brasil.leoloboo@gmail.com
}

CAROLINA SALDANHA SCHERER

Centro de Ciências Agrárias, Ambientais e Biológicas, UFRB, Rua Rui Barbosa, 710, 44380-000, Cruz das Almas, BA, Brasil.carolina_scherer@yahoo.com.br

MÁRIO ANDRÉ TRINDADE DANTAS

Instituto Multidisciplinar em Saúde, UFBA, Campus Anísio Teixeira, Rua Rio de Contas, n 58, 45029-094, Vitória da Conquista, BA, Brasil.matdantas@yahoo.com.br

\begin{abstract}
LATE PLEISTOCENE MEGAFAUNA FROM MATINA, BAHIA, BRAZIL: SYSTEMATIC, CHRONOLOGY AND PALEOECOLOGY. Fossils of Pleistocene mammals are well-represented in all Northeastern Brazil. In Bahia State these are found in caves and tanks fossiliferous outcrops. This paper focuses on the study of fossil mammals from the tank known as "Sítio Novo", in the municipality of Matina, Bahia. The research identified seven taxa: Megatheriidae (Megatheriinae, Eremotherium laurillardi), Mylodontidae, Glyptodontidae, Macraucheniidae (Macraucheninae, Xenorhinotherium bahiense), Toxodontidae, Gomphotheriidae (Notiomastodon platensis) e Camelidae. This locality has one of the most diverse records of extinct mammalian fauna until now among the tanks found in Bahia. Based on the studied assemblage and dates of the same taxa from this and others assemblages, we suggest that the local fauna lived during the late Pleistocene.
\end{abstract}

Key words: megafauna, mammals, paleoecology, chronology, late Pleistocene, Bahia.

RESUMO - Os fósseis de mamíferos pleistocênicos são bem representados em todo o Nordeste do Brasil. No Estado da Bahia são encontrados em depósitos de cavernas e tanques. O presente trabalho tem como foco o estudo de fósseis de mamíferos provenientes do tanque "Sítio Novo", Município de Matina, Bahia. Foram identificados sete táxons: Megatheriidae (Megatheriinae, Eremotherium laurillardi), Mylodontidae, Glyptodontidae, Macrauchenidade (Macraucheninae, Xenorhinotherium bahiense), Toxodontidae, Gomphotheriidade (Notiomastodon platensis) e Camelidae. Este depósito é um dos mais diversos registros de mastofauna extinta, conhecido até o momento, para tanques da Bahia. Com base na assembleia estudada e em datações dos mesmos táxons desta e de outras localidades, pode-se sugerir que esta fauna viveu durante o Pleistoceno final.

Palavras-chave: megafauna, mamíferos, paleoecologia, cronologia, Pleistoceno final, Bahia.

\section{INTRODUÇÃO}

Na Região Intertropical Brasileira - RIB (sensu Cartelle, 1999) os trabalhos sobre mamíferos pleistocênicos encontrados em depósitos fossilíferos do tipo tanque têm se intensificado nos últimos anos, com pesquisas nos estados de: Sergipe (e.g. Dantas et al., 2011), Alagoas (e.g. Dias Neto et al., 2008), Pernambuco (e.g. Silva et al., 2010), Paraíba (e.g. Bergqvist et al., 1997), Rio Grande do Norte (e.g. Porpino et al., 2009), Ceará (e.g. Ximenes, 2008) e Piauí (e.g. Guérin \& Faure, 2013).

No Estado da Bahia, fósseis da megafauna são encontrados em tanques e cavernas (e.g. Cartelle, 1992). As pesquisas realizadas em tanques já pontuaram a ocorrência de fósseis nos municípios de Vitória da Conquista (Dantas \& Tasso,
2007), Coronel João Sá (Dantas \& Zucon, 2007), Senhor do Bonfim (Xavier et al., 2008), Palmas de Monte Alto (Dantas et al., 2008), Quijingue (Bertoni-Machado et al., 2011), e em Baixa Grande (Ribeiro \& Carvalho, 2009).

Os fósseis encontrados em tanques pertencem, em sua grande maioria, os táxons de médio e grande porte, e no Estado da Bahia, até o momento, foram encontrados materiais de Eremotherium laurillardi (Lund, 1842), Notiomastodon platensis (Ameghino, 1888), Panochthus greslebini Castellanos, 1941 e Toxodontinae.

O presente trabalho registra novas ocorrências de fósseis da megafauna na localidade conhecida como "Sítio Novo", localizada no Município de Matina, Bahia, e apresenta a identificação e descrição anatômica dos espécimes coletados, tecendo comentários sobre a cronologia e a paleoecologia destes táxons. 


\section{MATERIAL E MÉTODOS}

\section{Área de estudo}

O material descrito provém de um tanque da localidade "Sítio Novo" (coordenadas UTM 23K 7242708461188, Datum WGS84), Município de Matina, Bahia, localizado na região sudoeste do estado, na porção limítrofe com a região do Médio São Francisco, a 719 km de Salvador (Figura 1).

Segundo Oliveira \& Hackspacher (1989) os tanques são formados por depressões naturais em uma rocha cristalina de idade pré-cambriana. Apresentam, normalmente, formato elíptico e paredes íngremes, e são preenchidos por sedimentos cascalhosos e arenosos de idade pleistocênica. Os sedimentos associados aos fósseis coletados no tanque "Sítio Novo" constituem-se de areia e sedimentos cascalhosos, ricos em feldspato e quartzo (Riff et al., 2008).

O material de estudo foi resgatado dos sedimentos previamente retirados do interior do tanque, os quais estão, atualmente, nas adjacências do mesmo. Assim sendo, não foi possível uma coleta ideal, carecendo observações tafonômicas e controle estratigráfico. Este acervo está depositado na coleção científica do Laboratório de Geologia da Universidade Estadual do Sudoeste da Bahia (LGUESB), Campus Vitória da Conquista.

\section{SISTEMÁTICA PALEONTOLÓGICA}

Ordem XENARTHRA Cope, 1889

Superfamília MEGATHERIOIDEA Gray, 1821

Família MEGATHERIIDAE Owen, 1843

Subfamília MEGATHERIINAE Gill, 1872

Eremotherium Spillmann, 1948

Eremotherium laurillardi (Lund, 1842)

(Figuras 2A-K; 3A-F)

Material. LGUESB 0048, fragmento de dentário esquerdo, com $\mathrm{m} 3$ e m4 (Figuras 2A-B); LGUESB 0043, lunar esquerdo
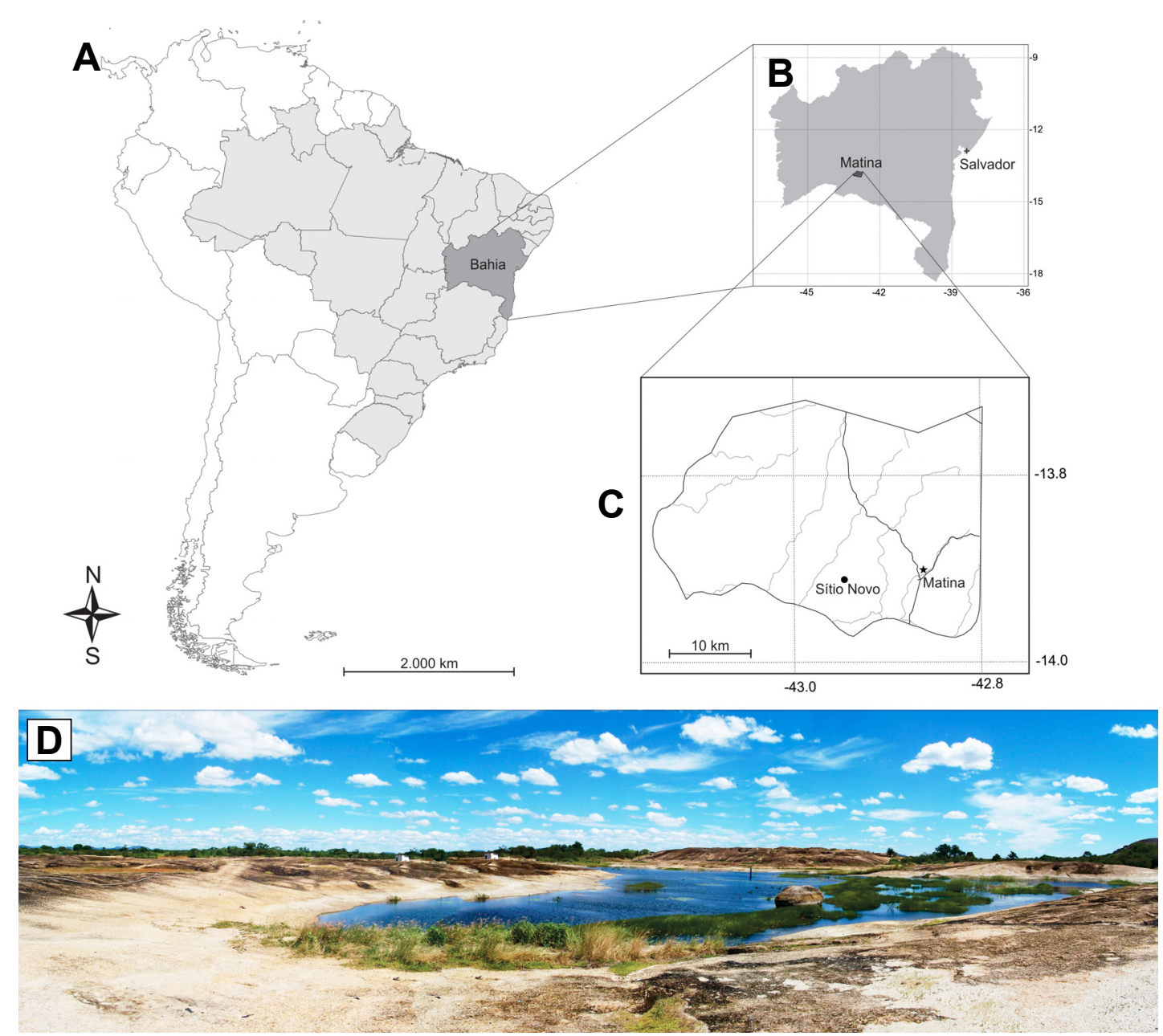

Figura 1. Localização do depósito fossilífero. A, mapa da América do Sul, em cinza claro o Brasil, e em cinza escuro o Estado da Bahia; B, mapa da Bahia delimitando o Município de Matina; C, Matina, delimitando o depósito fossilífero e o centro da cidade; D, localidade "Sítio Novo".

Figure 1. Location of the fossiliferous deposit. A, map of South America, Brazil in light gray, and State of Bahia in dark gray; B, map of Bahia delimiting the Matina Municipality; C, Matina, delimiting the fossiliferous deposit and the city center, D, locality "Sítio Novo". 
Tabela 1. Medidas $(\mathrm{mm})$ dos dentes inferiores de Eremotherium laurillardi. Abreviações: CMD, comprimento mésio-distal; LBL, largura buco-lingual.

Table 1. Measurements ( $\mathrm{mm}$ ) of Eremotherium laurillardi lower teeth. Abbreviations: CMD, mesiodistal length; LBL, buccolingual width.

\begin{tabular}{llcl}
\cline { 3 - 3 } & & CMD & LBL \\
\hline \multirow{2}{*}{ LGUESB 0048 } & $\mathrm{m} 3$ & 44,4 & 43,3 \\
& $\mathrm{~m} 4$ & 43,4 & 38,2 \\
\hline
\end{tabular}

(Figuras 2C-D); LGUESB 0049, lunar direito; LGUESB 0063, unciforme direito (Figuras 2E-F); LGUESB 0059, metacarpal IV esquerdo (Figuras 2G-I); LGUESB 0051, falange próximo-média esquerda; LGUESB 0052, falange próximo-média direita (Figuras 2J-K); LGUESB 0046, astrágalo direito (Figuras 3A-B); LGUESB 0034, fragmento anterior de calcâneo esquerdo (Figuras 3C-D); LGUESB 0035, navicular esquerdo (Figuras 3E-F).
Descrição. O fragmento de dentário LGUESB 0048 constituise apenas de uma pequena parte contendo dois molares ( $\mathrm{m} 3$ e m4). Na margem ventral do dentário, apenas foi preservada uma pequena parte, paralela ao $\mathrm{m} 4$, onde foi possível tomar a distância entre esta e a borda alveolar, de 108,6 mm. Posteriormente ao $\mathrm{m} 4$, está presente uma pequena parte do ramo ascendente. É possível visualizar o forame dentário, de formato elipsoide de 22,4 $\mathrm{mm}$ no seu maior diâmetro, localizado medialmente ao ramo ascendente na altura do $\mathrm{m} 4$. A dentição, presente somente no espécime LGUESB 0048 (Figuras 2A-B), consiste dos molariformes, m3 e m4 (Tabela 1). $\mathrm{O} \mathrm{m} 3$ está parcialmente fragmentado e o $\mathrm{m} 4$ se encontra inteiro. Os dentes são bilofodontes, apresentam formato prismático e seus lofos são paralelos entre si. No material, é ainda possível visualizar a cavidade pulpar do $\mathrm{m} 3$ a partir da borda inferior do dentário.

O osso lunar, representado pelos espécimes LGUESB 0043 (Figuras 2C-D) e LGUESB 0049, é um osso curto e com forma lateral de meia lua (Tabela 2). O osso lunar é o espécime melhor preservado, nele pode-se observar, na

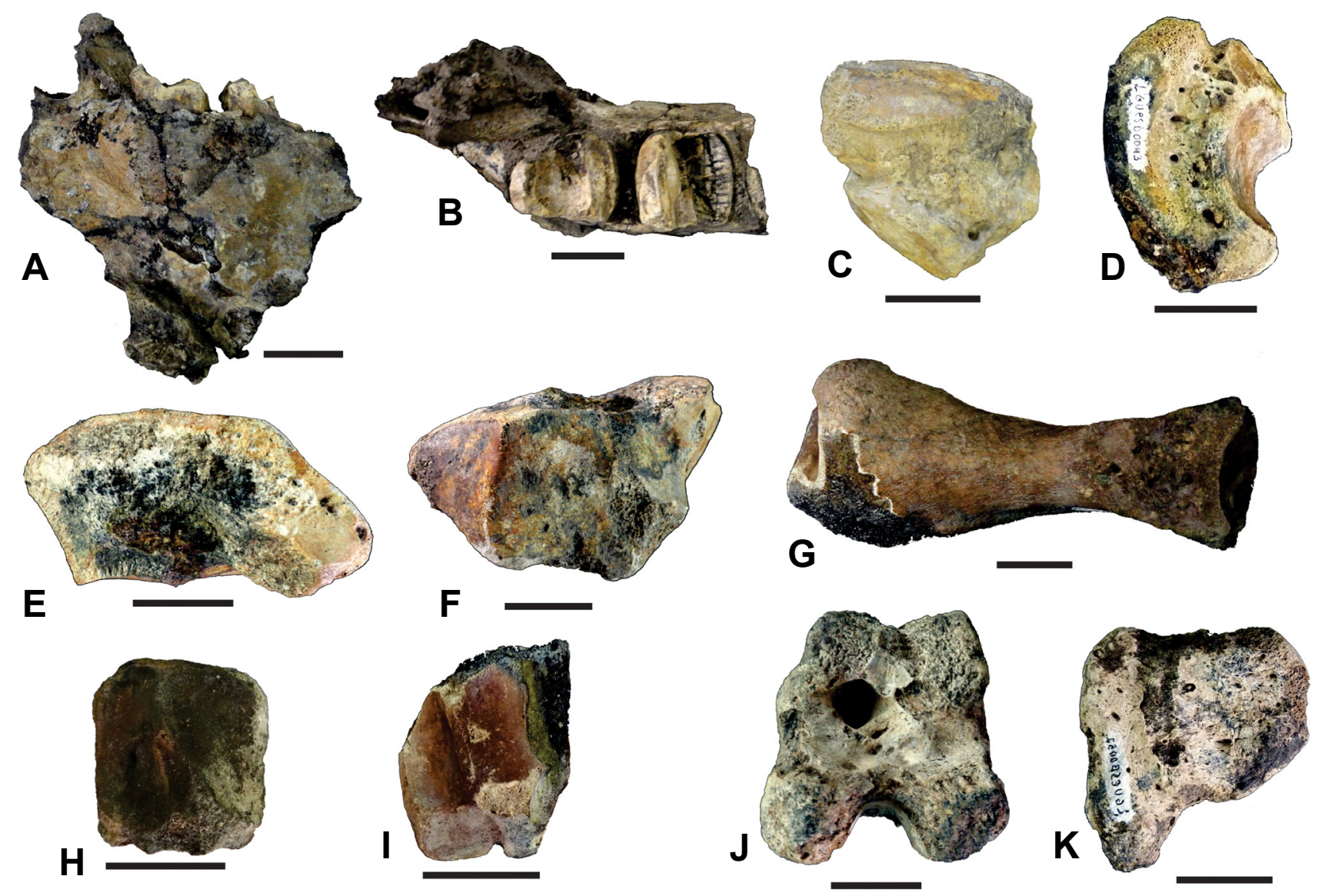

Figura 2. Eremotherium laurillardi, A-B, LGUESB 0048, fragmento de dentário esquerdo; A, vista medial; B, vista oclusal; C-D, LGUESB 0043, lunar esquerdo; C, vista dorsal; D, vista lateral; E-F, LGUESB 0063, unciforme direito; E, vista dorsal; F, vista distal; G-I, LGUESB 0059, metacarpal IV esquerdo; G, vista medial; H, vista proximal; I, vista distal; J-K, LGUESB 0051, falange proximo-média esquerda; J, vista palmar; $\mathbf{K}$, vista medial. Escalas $=50 \mathrm{~mm}$.

Figure 2. Eremotherium laurillardi, A-B, LGUESB 0048, fragment of left dentary; A, medial view; B, oclusal view; C-D, LGUESB 0043, left lunar; C, dorsal view; D, lateral view; E-F, LGUESB 0063, right unciform; E, dorsal view; F, distal view; G-I, LGUESB 0059, left metacarpal IV; G, medial view; H, proximal view; I, distal view; J-K, LGUESB 0051, proximal-middle left phalanx; J, palmar view; $\mathbf{K}$, medial view. Scale bars $=50 \mathrm{~mm}$. 
Tabela 2. Medidas (mm) dos ossos pós-cranianos de Eremotherium laurillardi. Abreviações: EDP, espessura dorso-palmar/plantar; CPD, comprimento próximo-distal; LML, largura médio-lateral.

Table 2. Measurements $(\mathrm{mm})$ of Eremotherium laurillardi postcranial bones. Abbreviations: EDP, dorsoplantar or dorsopalmar thickness; CPD, proximodistal length; $\mathbf{L M L}$, mediolateral width.

\begin{tabular}{lccc}
\cline { 2 - 4 } & EDP & CPD & LML \\
\hline Lunar & & & \\
LGUESB 0043 & 100,4 & 80,2 & 70,2 \\
LGUESB 0049 & & 76,7 & 80,5 \\
Uniciforme & & & \\
LGUESB 0063 & 71,4 & 64,2 & 127,1 \\
Metacarpal IV & & & \\
LGUESB 0059 & 58,5 & 265,6 & 62,6 \\
Falange Dígito III & & & \\
LGUESB 0051 & & 85,3 & 63,3 \\
LGUESB 0052 & & 94,1 & 82,8 \\
Astrágalo & & & \\
LGUESB 0046 & 197,6 & 199,2 & 220 \\
Extremidade anterior de Calcâneo & & & \\
LGUESB 0034 & 166,2 & & 218,1 \\
Navicular & & & \\
LGUESB 0035 & 72,3 & 62,3 & 127,8 \\
\hline
\end{tabular}

porção proximal, uma só faceta convexa, para articulação com a região distal do rádio. Na região lateral se observa uma faceta estreita ântero-posteriormente e alongada dorsopalmarmente, apresentando também leve concavidade; essa faceta articula-se com o cuneiforme. Tanto na região dorsal quanto na palmar, há superfícies rugosas e sem facetas. $\mathrm{Na}$ região distal do osso, estão as facetas para articulação com os ossos unciforme, magno e escafoide. A faceta para o unciforme é localizada lateralmente, é bastante côncava na sua porção palmar e torna-se plana e mais estendida distalmente na sua porção dorsal. Esta faceta é dividida das outras duas por uma crista intermediária, que atravessa a faceta no sentido dorso-palmar. As facetas para o magno e o escafoide apresentam uma divisão sutil entre elas, sendo que a primeira está localizada mais lateralmente e apresenta uma concavidade acentuada, enquanto que a segunda está localizada medialmente e é mais rasa.

O osso unciforme direito (Figuras 2E-F) é caracterizado pelo seu formato curto no sentido próximo-distal, estreito no sentido dorso-palmar e longo médio-lateralmente (Tabela 2). $\mathrm{Na}$ sua face proximal, apresenta duas facetas de articulação, uma lateral, convexa em forma de triângulo retângulo que se articula com o cuneiforme, e outra medial, levemente côncava e com formato de triângulo equilátero, que se articula com o lunar. Suas faces dorsal e palmar não apresentam facetas e têm superfícies rugosas. Na face distal, ele apresenta quatro facetas de articulação, que são delimitadas por leves cristas que as atravessam no sentido dorso-palmar. A faceta lateral apresenta formato triangular e é levemente côncava, esta se articula com o metacarpal $\mathrm{V}$; seguindo da região lateral para medial, a segunda faceta tem formato quadrangular e é levemente côncava, articula-se com o metacarpal IV; a terceira e quarta facetas articulam-se com o metacarpal III, porém a terceira faceta apresenta uma concavidade acentuada, seguida de uma convexidade que termina na quarta faceta, a qual apresenta formato triangular e tem superfície plana.

O metacarpal IV esquerdo (Figuras 2G-I) está quase completo, apresentando apenas leves deteriorações na parte dorso-distal (Tabela 2). Possui forma geral retangular, sendo mais afilado na região média do corpo do osso, tanto no seu plano dorso-palmar quanto médio-lateral. Na face proximal, apresenta lateralmente a faceta articular para o unciforme, a qual tem forma de triângulo retângulo e é levemente côncava. A faceta para o metacarpal III está voltada medialmente, porém encontra-se um tanto inclinada comparando-a com a faceta para o unciforme, ela também apresenta formato triângulo retangular e é côncava. Na face lateral da extremidade proximal, encontra-se a faceta para o metacarpal $\mathrm{V}$, a qual é levemente côncava e de contorno retangular. Distalmente às facetas para os metacarpais III e V, ocorrem rugosidades possivelmente para a inserção de ligamentos intercarpais. $\mathrm{Na}$ face distal, apresenta faceta articular para a falange proximal, a qual apresenta duas partes, a porção lateral é convexa e a medial é levemente côncava, ambas alongadas no sentido dorso-palmar. Na porção palmar ocorrem duas facetas planas e de contorno circular, para ossos sesamoides, as quais são contínuas com a faceta para a falange proximal-medial, sendo a medial de maior tamanho do que a lateral. Parte da porção distal dorsal está erodida superficialmente, assim não é possível visualizar as demais feições.

As falanges proximal e média fusionadas do dígito III, representadas pelos espécimes LGUESB 0051 e 0052 (Figuras 2J-K), constituem um só elemento (Tabela 2). Na parte proximal, é observada uma ampla faceta, com uma concavidade intermédia que se articula com a quilha distal do metacarpo III. Essa concavidade é mais alongada no sentido dorso-palmar do que no médio-lateral. Na região proximal, é possível visualizar, uma projeção lateral ou tubérculo ósseo lateral, voltado palmarmente. Na superfície articular distal, melhor conservada no espécime LGUESB 0051, pode-se observar a faceta ou tróclea para a falange ungueal. Essa faceta recobre todo o ápice da região distal, se estendendo da região dorsal até a região palmar.

O astrágalo direito (Figuras 3A-B) está completo, porém apresenta algumas facetas levemente erodidas (Tabela 2). A região proximal apresenta duas facetas articulares para a tíbia, sendo uma, o processo odontoide, caracterizada por formar uma projeção óssea proximalmente convexa e de forma grosseiramente cilíndrica. Esta faceta é semicircundada lateralmente pela maior faceta em extensão para a tíbia, a qual apresenta formato de semicírculo e é levemente convexa. Na porção ântero-medial a estas facetas, encontrase uma cavidade elipsoide para inserção de ligamentos, onde estão visíveis alguns forames vasculares. Na face anterior encontra-se a faceta, para o osso navicular, que é 

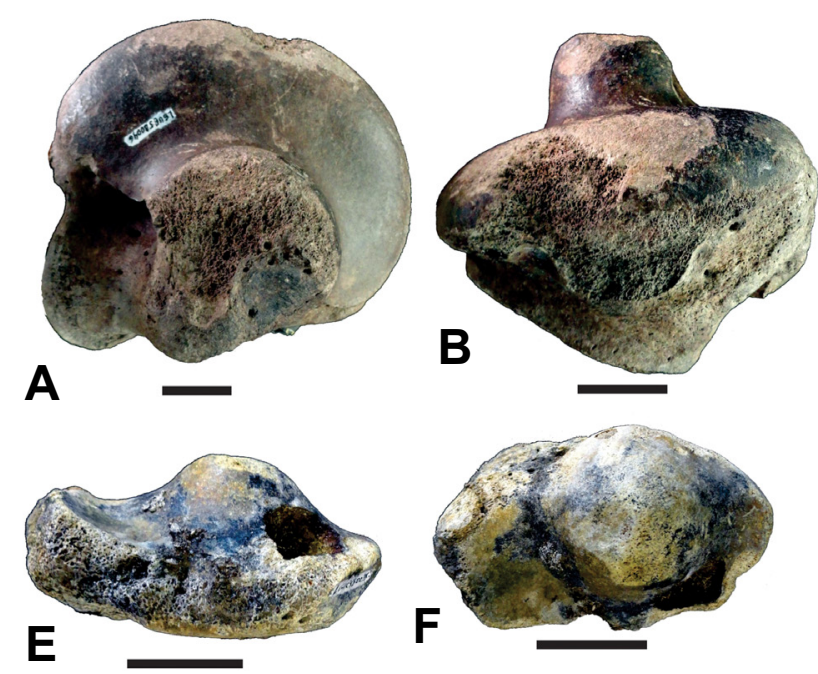

C
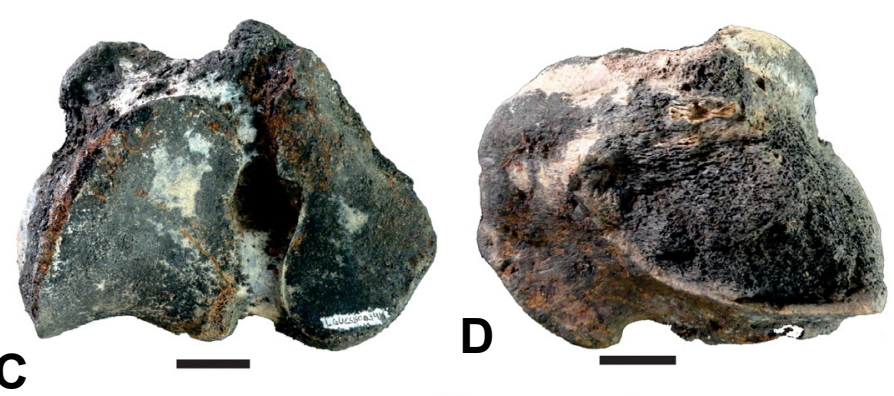

G
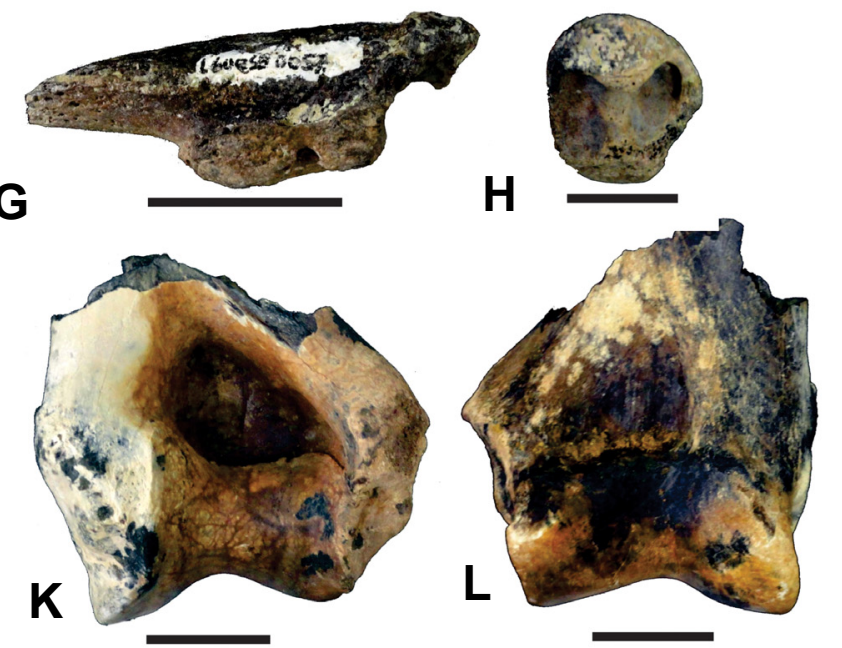

Figura 3. Eremotherium laurillardi, A-B, LGUESB 0046, astrágalo direito; A, vista proximal; B, vista lateral; C-D, LGUESB 0034, calcâneo esquerdo; C, vista proximal; D, vista posterior; E-F, LGUESB 0035, navicular esquerdo; E, vista dorsal; F, vista proximal. Mylodontinae, G-H, LGUESB 0057, falange ungueal direita; G, vista lateral; H, vista proximal. Glyptodontidae, I, LGUESB 0074, fragmentos de osteodermo, vista dorsal. Xenorhinotherium bahiense, J, LGUESB 0053, fragmento de vértebra torácica, vista cranial; K-L, LGUESB 0039, fragmento distal de úmero; K, vista posterior; L, vista anterior. Escalas $=50 \mathrm{~mm}$.

Figure 3. Eremotherium laurillardi, A-B, LGUESB 0046, right astragalus; A, proximal view; B, lateral view; C-D, LGUESB 0034, left calcaneum; C, proximal view; D, posterior view; E-F, LGUESB 0035, left navicular; E, dorsal view; F, proximal view. Mylodontinae, G-H, LGUESB 0057, right ungual phalanx; G, lateral view; H, proximal view. Glyptodontidae, I, LGUESB 0074, fragments of osteoderm, dorsal view. Xenorhinotherium bahiense, J, LGUESB 0053, fragment of thoracic vertebra, cranial view; K-L, LGUESB 0039, fragment distal of humerus; K, posterior view; $\mathbf{L}$, anterior view. Scale bars $=50 \mathrm{~mm}$.

caracterizada pelo contorno arredondado e côncavo. Contínua a esta concavidade, e circundando-a medialmente, está uma faceta alongada no sentido próximo-palmar e convexa, que se articula com o navicular e o cuboide. Em sua face plantar pode-se visualizar o sulcus talis, que percorre medianamente toda a parte distal do astrágalo, exatamente oposto à faceta medial da tíbia, que tem aspecto rugoso e uma série de forames vasculares. Também é possível visualizar as facetas para o calcâneo, separadas pelo referido sulco. A faceta medial ou sustentacular para o calcâneo é convexa e tem formato retangular, a qual se encontra posterior à faceta do cuboide e sua porção anterior é contínua com ela. A faceta lateral ou ectal é significativamente maior que a faceta medial, apresentando formato oval, com o maior diâmetro ântero-posterior, sendo caracterizada por sua extremidade posterior mais larga que a anterior. Essa faceta é côncava em seu maior diâmetro e levemente convexa no seu menor diâmetro.

O calcâneo esquerdo (Figuras 3C-D) está quase completo, faltando apenas a parte posterior referente ao tuber calcis ou tuberosidade do calcâneo (Tabela 2). Em sua região proximal, apresenta as faceta para articulação com o astrágalo, sendo divididas por um sulco profundo, o sulcus talis. A faceta lateral ou ectal, que apresenta maiores dimensões, tem forma oval e possui diâmetro ântero-posterior maior em relação ao médio-lateral. Ela é convexa no sentido dorso-plantar e levemente côncava no sentido médio-lateral. A faceta medial ou sustentacular apresenta formato alongado ânteroposteriormente e levemente côncavo no sentido dorso-plantar. Em direção à face plantar, essa faceta é contínua à faceta para com o cuboide. A parte plantar preservada apresenta superfície rugosa.

O osso navicular esquerdo (Figuras 3E-F) está quase completo, porém suas facetas distais estão erodidas (Tabela 2). A região proximal apresenta duas facetas articulares, uma faceta medial de formato semiesférico e convexo; e uma faceta lateral, que apresenta concavidade acentuada, sendo que ambas as facetas se articulam com o astrágalo. Tanto a face dorsal quanto a face plantar são rugosas e não apresentam facetas de articulação. A região distal apresenta formato geral convexo e apresenta duas facetas destinadas 
ao ectocuneiforme e entocuneiforme, porém estas facetas estão erodidas, não sendo possível observar maiores detalhes. Comentários. Paula-Couto (1979) refere-se ao gênero Eremotherium como sendo o mais primitivo morfologicamente, dentre os megaterídeos. Este gênero é comumente comparado com Megatherium por apresentar morfologia e distribuição próximas. Como exemplo, podem-se citar os trabalhos de De Iullis \& Cartelle (1993) e Cartelle \& De Iullis (1995), que compararam o crânio, dentes e ossos do carpo e tarso destes dois táxons. Esses gêneros são mais facilmente distinguidos entre si na morfologia do crânio e dos ossos carpais (Cartelle \& De Iuliis, 1995).

Eremotherium laurillardi é a espécie de preguiça terrícola com maior representatividade no território brasileiro e em toda a América do Sul intertropical, chegando até as Américas Central e do Norte (Cartelle \& De Iullis, 1995).

Os dentes $\mathrm{m} 3$ e $\mathrm{m} 4$ apresentam morfologia semelhante àquela descrita por Cartelle \& De Iullis (2006) e Cartelle et al . (2014). Também foram medidos e comparados com os $\mathrm{m} 3 \mathrm{e}$ $\mathrm{m} 4$ de Eremotherium mirabile (Leidy, 1855) $(=$ E. laurillardi, Cartelle \& De Iullis, 1995) descritos em Cartelle (1992), $E$. rusconii (Schaub, 1935) (= E. laurillardi, Cartelle \& De Iullis, 1995) descritos em Paula-Couto (1978), bem como aqueles descritos por Martinelli et al. (2012), apresentando dimensões semelhantes. Porém, vale salientar que, assim como apontado por Cartelle \& De Iullis (2006) e Cartelle et al. (2014), as dimensões dos molariformes alteram-se conforme o estádio ontogenético, aumentando a área oclusal conforme o desgaste do dente. Com base no material estudado e nas medições daqueles trabalhos, observa-se que o $\mathrm{m} 3$ apresenta maiores dimensões que o $\mathrm{m} 4$. O forame dentário, presente no espécime LGUESB 0048, está localizado na mesma região descrita para E. laurillardi (Cartelle \& De Iullis, 1995).

A maior quantidade de material coletado é referente ao esqueleto pós-craniano. Porém, não foi possível atribuir os espécimes a um mesmo indivíduo pela impossibilidade de articulação entre eles, o que pode ter sido causado, em parte, pela fragmentação e incompatibilidade de tamanho e morfologia das facetas articulares. Isso já foi observado por Abranches (2003), que afirma ocorrer grande variação intraespecífica no esqueleto apendicular de Eremotherium laurillardi, principalmente nos ossos do carpo e tarso.

Segundo Cartelle \& De Iullis (1995), os ossos podiais apresentam diferenças entre os representantes da família Megatheriidae, assim diferenciando as duas espécies, Eremotherium laurillardi e Megatherium americanum Cuvier, 1796. Os ossos pós-cranianos, condizem com as descrições dos materiais de E. laurillardi descritos por Cartelle (1992) e De Iuliis (1996). É valido salientar que nos trabalhos realizados em tanques do Estado da Bahia (e.g. Dantas \& Tasso, 2007; Dantas et al., 2008; Ribeiro \& Carvalho, 2009) a grande maioria dos ossos encontrados de E. laurillardi também são componentes do esqueleto apendicular.

Superfamília MYLODONTOIDEA Gill, 1872 Família MYLODONTIDAE Ameghino, 1889 (Figuras 3G-H)
Material. LGUESB 0057, falange ungueal direita (Figuras 3G-H).

Descrição. A falange ungueal do dígito II direito (Figuras 3G-H) está completa e apresenta formato de uma garra quase retilínea no sentido ântero-posterior (Tabela 3). $\mathrm{Na}$ porção proximal apresenta a faceta de articulação para a falange próximo-média. Essa faceta apresenta uma crista longitudinal convexa e alongada que a divide em duas porções côncavas, uma lateral e uma medial. Em sua porção proximal pode-se observar também o processo ungueal que circunda a faceta, sendo mais proeminente em sua região palmar. Na região palmar são visíveis os forames nutricionais. A partir da região proximal a falange ungueal vai se afinando progressivamente tanto na orientação dorsopalmar quando médio-lateral até sua porção distal.

Comentários. O único espécime aqui descrito foi comparado às descrições de falange ungueal de Eremotherium laurillardi realizadas por Cartelle (1992) e De Iuliis \& Cartelle (1993). Esta diferiu drasticamente, pois, E. laurillardi apresentam falanges ungueais de tamanho maior, curvatura mais acentuada e a faceta para a falange média é mais rasa do que no espécime em questão. De acordo com a descrição e ilustração apresentadas por Cartelle (1980), foi possível identificar o espécime como uma falange ungueal do dígito II da família Mylodontidae, por apresentar facetas mais delicadas e tamanho compatível com o material descrito e ilustrado por aquele autor. Paula-Couto (1979) menciona que as falanges da família Mylodontidae têm tendência a serem achatadas dorsoventralmente, o que também é observado no espécime descrito.

\section{Ordem CINGULATA Illiger, 1811 Família GLYPTODONTIDAE Burmeister, 1866}

(Figura 3I)

Material. LGUESB 0074, fragmento de osteodermo (Figura 3I). Descrição. O fragmento de osteodermo (Figura 3I) apresenta, em sua face dorsal, superfície rugosa, na qual é possível visualizar pequenos orifícios superficiais. Os osteodermos apresentam pequenas figuras que são utilizadas na identificação, porém devido ao estado fragmentário destas peças esta análise se tornou impossível.

Comentários. Os osteodermos dos Glyptodontidae podem ser tetra-, penta- ou hexagonais, com espessuras variáveis e, em sua face externa, apresentam uma série de sulcos e ornamentações. Tais estruturas apresentam diversas variações que são utilizadas na sistemática do grupo (Paula-Couto, 1979).

Tabela 3. Medidas ( $\mathrm{mm}$ ) da falange ungueal de Mylodontidae. Abreviações: EDP, espessura dorso-palmar; CPD, comprimento próximo-distal; LML, largura médio-lateral.

Table 3. Measurements $(\mathrm{mm})$ of Mylodontidae ungueal phalanx. Abbreviations: EDP, dorsopalmar thickness; CPD, proximodistal length; LML, mediolateral width.

\begin{tabular}{lccc}
\cline { 2 - 4 } & EDP & CPD & LML \\
\hline LGUESB 0057 & 36,6 & 102 & 26,2 \\
\hline
\end{tabular}


Fósseis da família Glyptodontidae são abundantes no Nordeste brasileiro, porém são ainda poucos os registros em tanques no Estado da Bahia. Por outro lado, há bons registros deste grupo em cavernas. Cartelle (1999) registrou para este estado, a ocorrência de Glyptodon clavipes (Owen, 1839), Panochthus greslebini e Hoplophorus euphracthus (Lund, 1839). Recentemente, Oliveira et al. (2010) e Zurita et al. (2011) realizaram uma revisão dos Glyptodontinae, considerando que o registro de Glyptodon na Bahia, e nos demais estados do Nordeste do Brasil, deveriam ser atribuídos a Glyptotherium sp. Para os tanques da Bahia, Ribeiro \& Carvalho (2009) relataram a ocorrência da espécie P. greslebini no Município de Baixa Grande, Bahia. Porém, Porpino et al. (2014) não atribuíram o material proveniente da Bahia a nenhuma das espécies de Panochthus. Por estar bastante incompleto e erodido, não foi possível identificar o espécime em nível genérico e específico.

Ordem LITOPTERNA Ameghino, 1889

Subordem LOPHOLIPTERNA Cifelli, 1983

Família MACRAUCHENIIDAE Gervais, 1855

Xenorhinotherium Cartelle \& Lessa, 1988

Xenorhinotherium bahiense Cartelle \& Lessa, 1988 (Figuras 3J-L)

Material. LGUESB 0053, vértebra torácica (Figura 3J); LGUESB 0039, fragmento distal do úmero direito (Figuras 3K-L). Descrição. $O$ fragmento de vértebra torácica (Figura 3J) contém apenas o corpo vertebral e uma pequena porção do arco neural (Tabela 4). Em sua face cranial, o corpo vertebral apresenta formato subcircular e levemente convexo, e a face caudal também apresenta formato subcircular, porém com a superfície retilínea. Lateralmente ao corpo vertebral, na face cranial e caudal, ocorrem facetas para articulação com o capítulo da costela. Essas facetas, na face cranial, são ligeiramente inclinadas em relação à face anterior do corpo vertebral, são côncavas e apresentam formato oval com seu maior diâmetro no sentido dorso-ventral. As facetas caudais

Tabela 4. Medidas ( $\mathrm{mm}$ ) dos ossos pós-cranianos de Xenorhinotherium bahiense. Abreviações: ADV, altura dorso-ventral; $\mathbf{C C C}$, comprimento crânio-caudal; LML, largura médio-lateral; EEL, espessura (ânteroposterior) do epicôndilo lateral; EEM, espessura (ântero-posterior) epicôndilo medial; LD, largura distal (médio-lateral).

Table 4. Measurements (mm) of Xenorhinotherium bahiense postcranial bones. Abbreviations: ADV, dorsoventral height; CCC, craniocaudal length; LML, mediolateral width; EEL, thickness (anteroposterior) of lateral epicondyle; EEM, thickness (anteroposterior) of medial epicondyle; LD, distal width (mediolateral).

\begin{tabular}{lccc}
\cline { 2 - 4 } & ADV & CCC & LML \\
\hline Vértebra torácica & & & \\
LGUESB 0053 & 46 & 53,1 & 94,7 \\
& EEL & EEM & LD \\
Extremidade Distal de úmero & & & \\
LGUESB 0039 & 71,2 & 84 & 120,8 \\
\hline
\end{tabular}

que se articulam com o capítulo da costela são retilíneas em relação ao côndilo articular caudal, elas são côncavas e apresentam formato oval com seu maior diâmetro no sentido dorso-ventral. A região dorsal do corpo vertebral tem superfície quase retilínea enquanto na região ventral da vértebra ocorre uma crista no corpo vertebral.

$\mathrm{O}$ fragmento de úmero direito (Figuras $3 \mathrm{~K}-\mathrm{L}$ ) consiste da porção distal do osso (Tabela 4). Na região anterior apresenta fossa coronoide levemente côncava. As faces, lateral e medial, dos côndilos são achatadas, porém a face do epicôndilo lateral apresenta uma projeção óssea logo acima do côndilo. $\mathrm{Na}$ face posterior da tróclea é observada a fossa olecraniana que abriga a apófise olecraniana-ulnar; essa fossa é profunda e com formato elíptico.

Comentários. Os espécimes LGUESB 0039 e LGUESB 0053 foram comparados quanto à morfologia e tamanho com os trabalho de Owen (1838) e Scherer et al. (2009), e estes são bastante similares, motivo pelo qual o material aqui apresentado foi atribuído a família Macraucheniidae.

Os materiais de Macraucheniidae encontrados no Brasil intertropical foram atribuídos por Cartelle \& Lessa (1988) a Xenorhinotherium bahiense, espécie descrita por eles com base em caracteres cranianos distintos de Macrauchenia patachonica Owen, 1838, espécie que apresenta distribuição geográfica restrita à porção sul da América do Sul. Guérin \& Faure (2004) sinonimizam as duas espécies anteriormente citadas através de material oriundo de uma caverna localizada no Estado do Piauí, entretanto esta proposta não tem sido suportada pelos trabalhos recentes, sendo necessária uma revisão (Scherer et al., 2009; Schmidt \& Ferrero, 2014). O material pós-craniano de Macraucheniinae apresenta pequenas diferenças entre os táxons (Cartelle \& Lessa, 1988; Scherer et al., 2009). Devido à ausência de caracteres que diferenciam o material estudado daquele de $X$. bahiense e seguindo-se a proposta biogeográfica de Cartelle (1999), sugere-se que o material estudado pertence a esta espécie.

\section{Ordem NOTOUNGULATA Roth, 1903 \\ Subordem TOXODONTIA Owen, 1853 TOXODONTIDAE Owen, 1845 \\ (Figuras 4A-E)}

Material. LGUESB 0066, fragmento distal do rádio esquerdo (Figura 4A); LGUESB 0054, falange proximal do dedo II (Figuras 4D-E); LGUESB 0067, calcâneo direito (Figuras 4B-C). Descrição. $O$ fragmento de rádio esquerdo (Figura $4 \mathrm{~A}$ ) consta apenas da parte distal do osso (Tabela 5). É possível observar que a extremidade distal do osso apresenta um progressivo aumento na espessura ântero-posterior em relação ao corpo do osso. Na face articular distal é possível visualizar duas facetas de articulação, uma medial e acentuadamente côncava, onde se articula o escafoide, e outra, posicionada lateralmente, mais projetada distalmente que a anterior e levemente côncava, que se articula com o osso lunar.

O calcâneo direito (Figuras 4B-C) apresenta-se quase completo, tendo melhor preservada a região proximal, enquanto a porção mais distal do tuber calcis ou tuberosidade 
do calcâneo está bastante erodida. A parte proximal do osso também se encontra um pouco erodida, assim não apresenta as facetas proximais que articulam com a fíbula e o astrágalo. $\mathrm{Na}$ região proximal do osso ocorre lateralmente uma faceta com formato de meia lua e côncava para o astrágalo. Na parte próximo-plantar é possível visualizar uma faceta maior, de contorno elíptico e plano para o cuboide e, lateralmente a ela, parte de uma faceta que seria para o navicular.

A falange proximal do dígito II (Figuras 4D-E) está quase completa, faltando apenas parte da faceta proximal (Tabela 5). É um osso curto e largo, apresenta apenas duas facetas em sua totalidade, uma proximal e uma distal. Sua faceta proximal é oval e levemente côncava, tendo seu maior diâmetro médiolateral. Na sua região distal, apresenta uma faceta menor que a faceta da região proximal, mas que também apresenta formato oval, porém retilíneo.

Comentários. Cartelle (1992) relata a dificuldade de identificação das espécies de Toxodontidae com base no esqueleto pós-craniano, principalmente pelo alto grau de similaridade dos ossos. O mesmo autor assinala ainda a presença de Toxodon platensis e Trigodonops lopesi para o Pleistoceno intertropical brasileiro, porém de acordo com Bond et al. (2006) T. lopesi é um táxon do Neógeno da América do Sul. Recentemente foi descrita uma nova espécie de Toxodontidae para o Estado do Piauí,
Tabela 5. Medidas (mm) dos ossos pós-cranianos de Toxodontidae. Abreviações: EAP, espessura ântero-posterior; CPD, comprimento próximo-distal; LML, largura médio-lateral.

Table 5. Measurements $(\mathrm{mm})$ of Toxodontidae postcranial bones. Abbreviations: EAP, anteroposterior thickness; CPD, proximodistal length; LML, mediolateral width.

EAP $\quad$ CPD $\quad$ LML

Extremidade distal de rádio

LGUESB 0066

67,2

92,2

Falange proximal

LGUESB 0054

37,4

$31,7 \quad 43,1$

Piauhytherium capivarae Guérin \& Faure, 2013, na qual os autores incluem alguns espécimes antes atribuídos a Trigodonops sp. e Mixotoxodon sp. procedentes do mesmo estado (Guérin \& Faure, 2013). Dessa forma, são registrados, até o momento, apenas os gêneros Toxodon e Piauhytherium para a RIB.

Os elementos ósseos estudados foram comparados com as descrições, medições e ilustrações apresentadas por Roth (1898), sendo semelhantes ao material referido por este autor. Porém, Góes et al. (2002) afirmaram que os
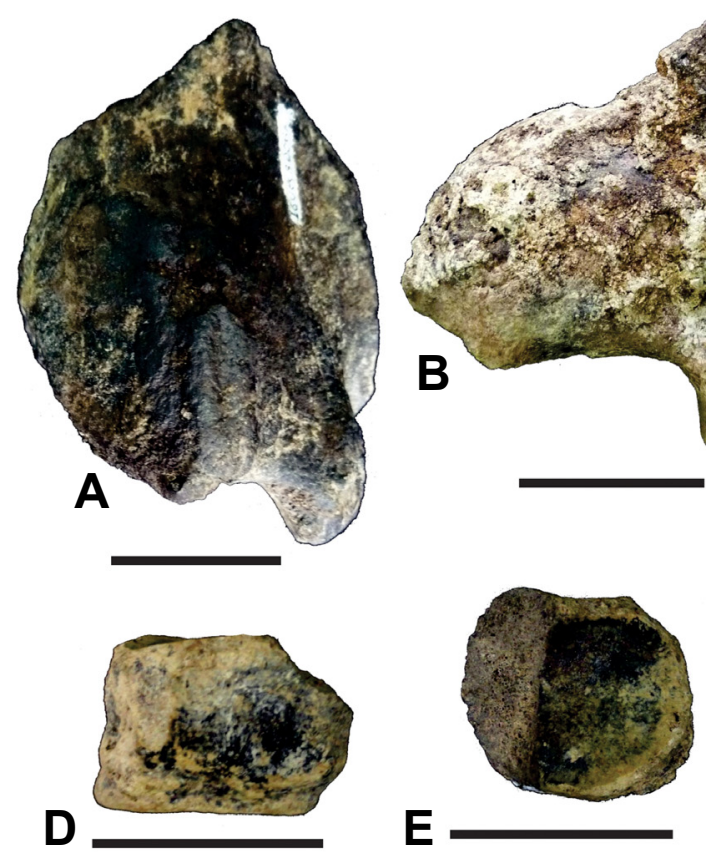
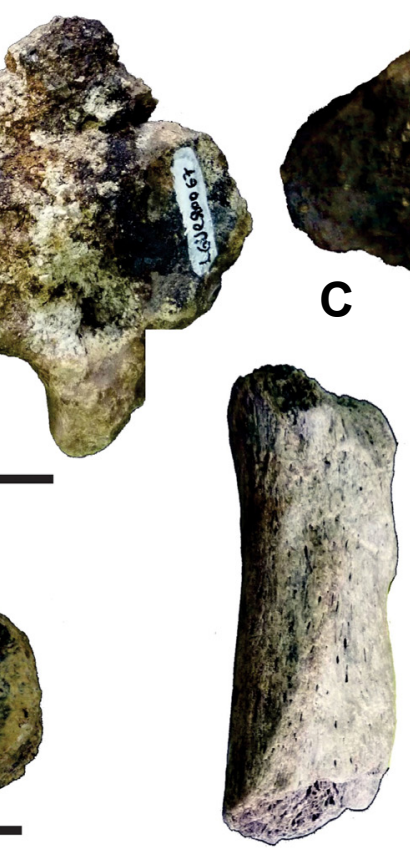

$\mathbf{F}$

C

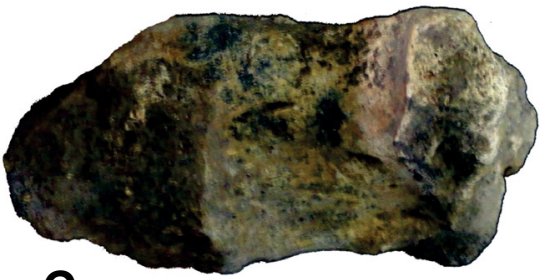

G

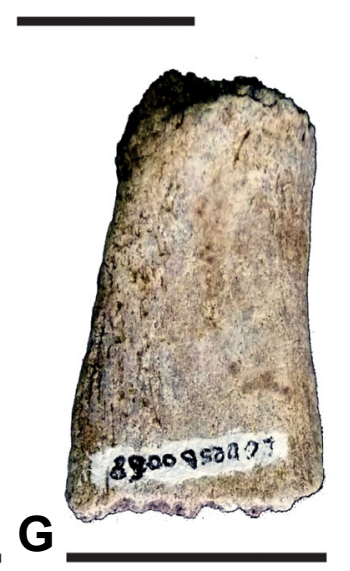

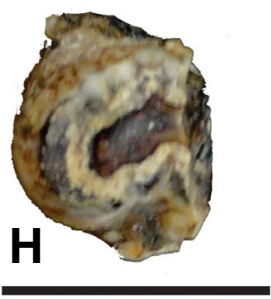

Figura 4. Toxodontidae, A, LGUESB 0066, fragmento distal do radio esquerdo, vista anterior; B-C, LGUESB 0067, calcâneo direito; B, vista posterior; C, vista medial; D-E, LGUESB 0054, falange proximal do dedo II; D, vista dorsal; E, vista proximal. Camelidae, F-G, LGUESB 0068, fragmento posterior do calcâneo; F, vista dorsal; G, vista lateral. Notiomastodon platensis, H, LGUESB 0047, fragmento de molar, vista oclusal. Escalas $=50 \mathrm{~mm}$.

Figure 4. Toxodontidae, A, LGUESB 0066, fragment distal of left radius, anterior view; B-C, LGUESB 0067, right calcaneum; B, posterior view; C, medial view; D-E, LGUESB 0054, proximal phalanx of digit II; D, dorsal view; E, proximal view, Camelidae. F-G, LGUESB 0068, fragment posterior of calcaneum; F, dorsal view; G, lateral view. Notiomastodon platensis, H, LGUESB 0047, fragment of molar, oclusal view. Scale bars $=50 \mathrm{~mm}$. 
elementos ósseos pós-cranianos de Toxodontidae somente são distinguíveis entre as espécies através de comparações acuradas e utilizando-se um grande número de espécimes. Portanto, tornou-se difícil a identificação específica ou genérica do material aqui descrito por tratar-se de elementos pós-cranianos isolados.

\section{Ordem PROBOSCIDEA Illiger, 1811 Família GOMPHOTHERIIDAE Hay, 1922}

Notiomastodon Cabrera, 1929

Notiomastodon platensis (Ameghino, 1888) (Figura 4H)

Material. LGUESB 0047, fragmento de molar.

Descrição. Fragmento de molar (Figura $4 \mathrm{H}$ ) consistindo apenas de parte de um lofo. Devido ao grau de fragmentação do material, não se pode observar maiores detalhes, apenas que o dente apresenta desgaste.

Comentários. Mothé et al. (2012) realizaram uma revisão taxonômica dos gonfoterídeos do Quaternário da América do Sul que viveram em baixas altitudes, reduzindo a ocorrência do grupo para apenas um gênero e espécie: Notiomastodon platensis, cujo táxon apresenta grande distribuição geográfica (Mothé et al., 2012; Dantas et al., 2013a).

Os dentes de Gomphotheriidae têm como característica principal a superfície oclusal em forma de "trevos", que é o padrão de arranjo das cúspides dessa família (Mothé et al., 2012). O fragmento aqui apresentado consiste somente de parte de uma cúspide com avançado grau de desgaste, pelo que não foi possível compará-los com as diagnoses das espécies conhecidas.

A presença de Notiomastodon platensis foi relatada para tanques no Estado da Bahia para Baixa Grande (Ribeiro \& Carvalho, 2009), e Vitória da Conquista (Dantas \& Tasso, 2007), todos estes registros foram através de fragmentos de dentes molariformes e incisivos.

ARTIODACTYLA Owen, 1848

Subordem TYLOPODA Illiger, 1811

Família CAMELIDAE Gray, 1821

(Figuras 4F-G)

Material. LGUESB 0068, fragmento posterior do calcâneo. Descrição. O fragmento de calcâneo (Figuras 4F-G) apresenta apenas a porção da tuberosidade, porém esta está com seu ápice erodido. Apresenta formato longo e delgado. $\mathrm{Na}$ face lateral, ele apresenta uma superfície retilínea, e à medida que se afasta da tuberosidade é expandido ânteroposteriormente. Na região distal do ápice da tuberosidade ocorre uma elevação óssea que se projeta medialmente, criando dois sulcos, que servem para inserção do tendão calcanear comum. No material não foi preservada nenhuma faceta referente à região proximal.

Comentários. O espécime estudado trata-se da porção posterior do calcâneo, apresentando somente a tuberosidade calcanear, motivo pelo qual, não se pode identificá-lo especificamente. O táxon de Camelidae mais comum no Nordeste do Brasil é Palaeolama major, inclusive já tendo sido referido para a Bahia (Cartelle, 1999; Scherer, 2009). Cartelle (1994) também descreveu material pertencente a Lama guanicoe para este estado. Altamirano (2006) identificou duas espécies, Palaeolama weddeli e Lama sp., no sitio paleontológico da Toca da Boa Esperança, localizada no Município Central, Estado da Bahia. Como mencionado, o material estudado não permite identificação genérica ou específica, apesar de seu tamanho ser comparável a de Palaeolama, porém este registro torna-se relevante já que trata-se do primeiro registro de Camelidae em um depósito do tipo tanque na Bahia.

\section{DISCUSSÃO}

Para o tanque de Sítio Novo, Matina, Estado da Bahia há apenas uma datação, adquirida pela técnica de Ressonância de Spin Electrônico - RSE, em um fóssil de Notiomastodon platensis situando-o a sua ocorrência por volta de $100 \pm 20$ mil anos (Dantas et al., 2013a). Esta é uma das datações mais antigas encontradas em tanques da Região Intertropical Brasileira - RIB, em conjunto com a de $114 \pm 20$ mil anos AP (técnica RSE; Dantas et al., 2013a) encontrada para um fóssil da mesma espécie em um tanque de Jaguarari, Bahia. Esta espécie é a que possui o maior número de datações disponíveis, apresentando um intervalo cronológico na RIB, considerando-se seus erros padrões máximos e mínimos, entre 120 a 5 mil anos AP (ver revisão das datações disponíveis em França et al., 2014).

Além de Notiomastodon platensis, foram encontrados neste tanque fósseis de Eremotherium laurillardi, Xenorhinotherium bahiense, Toxodontinae, Mylodontidae, Glyptodontidae e Camelidae. A ocorrência destes táxons é geralmente atribuída ao Pleistoceno final (e.g. Cartelle, 1999), no entanto, nos últimos anos um número crescente de datações (realizadas através das técnicas de radiocarbono $-{ }^{14} \mathrm{C}$ AMS; Ressonância de Spin Eletrônico; Urânio-Tório - U-series) trouxeram um maior refinamento para espécies nesta região.

Para Eremotherium laurillardi há datações realizadas por duas técnicas: U-series e radiocarbono. Aúnica datação direta realizada pelo método U-series foi apresentada por Auler et al. (2006), que chegaram a idade de 15 mil anos AP (Bahia), as demais datações foram realizadas ${ }^{14} \mathrm{C}$ (Bahia, Drefahl, 2010; Rio Grande do Norte, Sergipe e Bahia, Dantas et al., 2013b; Sergipe, França et al., 2014). Há também datações indiretas, realizadas por U-series, em ossos não identificados encontrados na mesma camada que fósseis de $E$. laurillardi $\mathrm{em}$ um tanque em Central, Bahia, que sugerem a ocorrência desta espécie há 295 a 204 mil anos AP (Beltrão \& Locks, 1989). Se estas datações forem consideradas, indicam a ocorrência desta espécie em um intervalo cronológico entre 295 a $11 \mathrm{mil}$ anos AP, considerando apenas as datações diretas, o intervalo seria restringido entre 27 a 11 mil anos AP.

Para membros da família Glyptodontidae não há datações disponíveis para fósseis coletados na RIB. No entanto, Piló 
Tabela 6. Mistura temporal observada nos tanques da Fazenda São José (Poço Redondo, Sergipe) e da Lagoa do Rumo (Baixa Grande, Bahia). Abreviações: Tq I, Fazenda São José; Tq II, Lagoa do Rumo; EI, Eremotherium laurillardi; Np, Notiomastodon platensis; Tx, Toxodon platensis.

Table 6. Temporal averaging observed in the tanks of Fazenda São José (Poço Redondo, Sergipe) and Lagoa do Rumo (Baixa Grande, Bahia). Abbreviations: Tq I, Fazenda São José; Tq II, Lagoa do Rumo; EI, Eremotherium laurillardi; Np, Notiomastodon platensis; Tx, Toxodon platensis.

\begin{tabular}{|c|c|c|c|c|c|c|c|c|c|c|c|c|c|}
\hline \multirow{2}{*}{ Táxons } & \multicolumn{13}{|c|}{ Idade (mil anos AP) } \\
\hline & 7 & 12 & 17 & 22 & 27 & 32 & 37 & 42 & 47 & 52 & 57 & 62 & 67 \\
\hline
\end{tabular}

$\mathrm{Tq} 1$

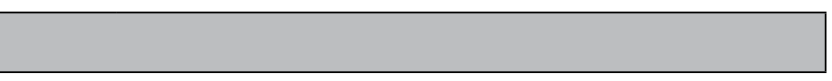

El

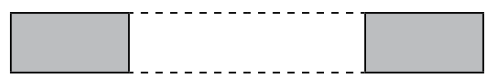

$\mathrm{Np}$

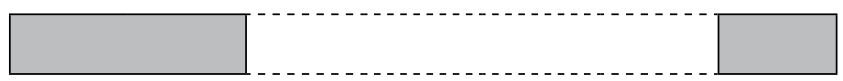

$\mathrm{Tq} 2$

$\mathrm{Tx}$

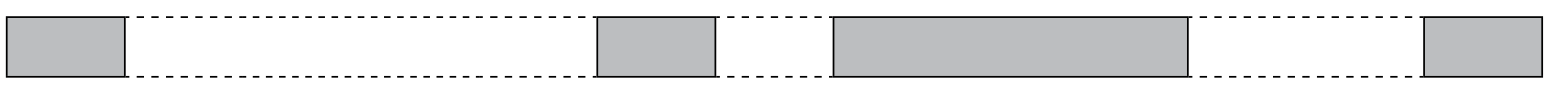

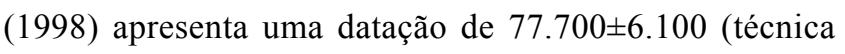
U-series) para Hoplophorus euphractus (Minas Gerais), e Hubbe et al. (2011), através de ${ }^{14} \mathrm{C}$, encontraram para Glyptodon clavipes (São Paulo) uma idade de 20.680-21. 370 anos AP, sendo estas as únicas datações disponíveis no Brasil para esta família até o momento.

Para a subfamília Toxodontinae existem vinte datações para esta região (Sergipe, Dantas et al., 2011; Rio Grande do Norte, Sergipe e Bahia, Dantas et al., 2013b; Bahia, Ribeiro et al., 2013; 2014), realizadas através do método RSE e ${ }^{14} \mathrm{C}$, que sugerem a ocorrência de representantes desta subfamília entre 66 mil anos e 7 mil anos AP.

A única datação disponível para Xenorhinotherium bahiense é a apresentada por Kinoshita et al. (2005), encontrada através da técnica RSE, que indica uma idade de $39 \pm 9$ mil anos AP em fósseis coletados no Estado da Paraíba.

Por último, para Palaeolama major (família Camelidae) há uma datação de 350.000 anos AP em Minas Gerais (técnica U-series, Auler et al., 2006). No Nordeste brasileiro, a única datação é a apresentada por Dantas et al. (2011) em que situa a ocorrência desta espécie em Sergipe há 38 mil anos AP.

Estas datações fornecem uma estimativa de quando os táxons encontrados no tanque Sítio Novo viveram, mas hoje sabe-se que neste tipo de depósito é comum a mistura temporal dos fósseis. Este tipo de evento já foi documentado em tanques com ocorrência simultânea de diferentes tipos de processos, como diagenéticos e abrasão que levam a quebras nos ossos (e.g. Santos et al., 2002; Araújo-Júnior et al., 2013). Mas, nos últimos anos, novas evidências foram trazidas de datações diretas em fósseis. Há datações para, pelo menos, três táxons ocorrentes em dois tanques da RIB. No tanque da Fazenda São José, Poço Redondo, no Estado de Sergipe, datações (radiocarbônicas $-{ }^{14} \mathrm{C}$ AMS; Ressonância de Spin Eletrônico - RSE) para Eremotherium laurillardi (entre $11 \mathrm{e}$ 27 mil anos AP; Dantas et al., 2013b; França et al., 2014) e Notiomastodon platensis (entre 12 e 42 mil anos AP; Dantas et al., 2011; França et al., 2014) indicam uma taxa de mistura temporal máxima de 31 mil anos (Tabela 6). No tanque de Lagoa do Rumo, Baixa Grande, Bahia, foi observado uma taxa de mistura temporal mais ampla, 59 mil anos (Tabela 6), segundo as datações em fósseis de Toxodon platensis (técnica RSE; Ribeiro et al., 2014).

Estes dados demonstram que os tanques, em relação a outros tipos de depósitos, possuem, comparativamente, uma alta resolução temporal. Apesar de não existirem múltiplas datações para avaliar qual seria a taxa de mistura temporal deste tanque, considera-se aqui a hipótese de que esta taxa seria de 40 mil anos AP, com base na datação de $100 \pm 20$ mil anos encontrada para Notiomastodon platensis, que seria uma taxa de mistura temporal compatível com aquelas constatadas em outros afloramentos.

Com relação aos dados paleoecológicos, Auler \& Smart (2001), Wang et al. (2004) e Barreto (2010) afirmam que entre 130 e 97 mil AP anos houve um período prolongado de umidade para um período quente e seco, com pequenos intervalos de umidade, e apesar de não haver dados palinológicos para comprovar o tipo de vegetação que predominava, é provável que as áreas de Caatinga e Cerrado estivessem reduzidas e isoladas, enquanto possíveis conexões entre as florestas Amazônica e Atlântica pudessem estar ocorrendo.

Dentre os táxons encontrados na localidade Sítio Novo, observamos que alguns deles possuíam uma dieta ampla, 
que incluía o consumo de plantas $\mathrm{C}_{3}$ (e.g. frutas, folhas), um indicativo de consumo de recursos em bordas de florestas. Eremotherium laurillardi, espécie de distribuição panamericana, deveria apresentar hábitos alimentares generalistas, podendo se alimentar de gramíneas, ramos e folhas de árvores de maior porte (McDonald, 2005). Esta interpretação foi corroborada por análise de isótopos de carbono em fósseis coletados nos estados do Rio Grande do Norte, Alagoas, Sergipe e Bahia (Drefahl, 2010; Viana et al., 2011; Dantas et al., 2013b; França et al., 2014).

MacFadden (2005) a partir de dados de isótopos de carbono em dentes de Toxodon encontrados em uma caverna em Ourolândia, Estado da Bahia, obteve valor médio de $\delta^{13} \mathrm{C}=-8.6 \%$ (variando de $\delta^{13} \mathrm{C}=-12.6 \%$ a $5.5 \%$ ), concluindo que os toxodontes possuíam uma dieta mista, com consumo de plantas $\mathrm{C}_{3}$ e $\mathrm{C}_{4}$. Outros valores similares para dietas de toxodontes foram encontrados nos estados de Alagoas $\left(\delta^{13} \mathrm{C}=-4.10 \%\right.$, Viana et al., 2011) e Sergipe $\left(\delta^{13} \mathrm{C}=-3.68 \%\right.$, Dantas et al., 2013b). Entretanto, uma dieta exclusiva em plantas $\mathrm{C}_{3}\left(\delta^{13} \mathrm{C}=-13.24 \%\right.$, Dantas et al., 2013b) foi observada em um espécime de toxodonte coletado em Vitória da Conquista, no estado de Bahia. Estes dados mostram o hábito mais generalista do táxon.

Asevedo et al. (2012), a partir de analises de microdesgaste e recuperação de microvegetais, sugerem que Notiomastodon platensis viveria sob condições climáticas tanto tropicais quanto temperadas, com dieta alimentar mista e flexível, podendo apresentar hábito ramoneador arbustivo ou pastador de gramíneas, interpretação confirmada pelos resultados de razão isotópica de carbono realizados em fósseis dos estados dos estados de Alagoas (Viana et al., 2011), Rio Grande do Norte, Sergipe e Bahia (Dantas et al., 2013b; França et al., 2014).

Marcolino et al. (2012) observaram cristais e sedimentos em coprólitos de Palaeloma major, da Gruta dos Brejões, Morro do Chapéu, Estado da Bahia, sugerindo assim que este táxon vivia em áreas de fronteira de floresta, fortalecendo, deste modo, a interpretação de Cartelle (1992) de que sua alimentação consistiria principalmente de arbustos, ao contrário de gramíneas.

Segundo Cartelle (1992), os gliptodontídeos poderiam apresentar hábito fossorial, com intuito de se alimentar de raízes, por apresentarem fortes garras nas extremidades anteriores e pela presença de camada central de ortodentina nos molariformes, o que possibilitaria uma dieta de maior consistência. Já Fariña \& Vizcaíno (2001) sugeriram, a partir de características dentárias, hipsodontia e grande número de molares, que os gliptodontídeos poderiam apresentar hábito pastador. Pérez-Crespo et al. (2012) estudando a dieta de Glyptotherium sp. proveniente de Cedral, México, através de análises de isótopos de carbono, concluíram que a dieta deste táxon seria mista, entre plantas $\mathrm{C}_{3}$ e $\mathrm{C}_{4}$, com uma dominância de plantas $\mathrm{C}_{4}$, corroborando a hipótese de Fariña \& Vizcaíno (2001).

Cartelle (1992) caracterizou Xenorhinotherium bahiense como de hábito pastador, afirmativa apoiada pela sua dentição, apresentando incisivos e caninos cortantes e agudos e pré- molares tendendo a molarização, tornando eficiente a ingestão de gramíneas.

O único representantes dos Macrauqueniinae com dados paleoecológicos mais concretos é Macrauchenia patachonica. MacFadden \& Shockey (1997) e França et al. (2015) apresentaram dados de isótopos de carbono para Macrauchenia patachonica e concluíram que este táxon teria uma alimentação mista, ingerindo tanto plantas $\mathrm{C}_{3}$ como $\mathrm{C}_{4}$. Assim, é necessário um estudo mais aprofundado acerca da paleoecologia de Xenorhinotherium bahiense.

\section{CONCLUSÕES}

No presente trabalho são descritos fósseis pertencentes a sete táxons: Megatheriidae (Megatheriinae, Eremotherium laurillardi), Mylodontidae, Glyptodontidae, Macrauchenidade (Macraucheniinae, Xenorhinotherium bahiense), Toxodontidae (Toxodontinae), Gomphotheriidade (Notiomastodon platensis) e Camelidae, encontrados no tanque do Sítio Novo, Matina, Estado da Bahia. É válido salientar que a maioria dos fósseis descritos para este depósito refere-se a ossos do carpo ou tarso.

Os táxons estudados podem ser representantes de uma única paleocomunidade que, baseado na datação encontrada em Notiomastodon platensis, existiu há $100.000 \pm 20.000$ anos AP.

\section{AGRADECIMENTOS}

A A.L. Sanches e E.S. Bernardes (Laboratório de Geologia da Universidade Estadual do Sudoeste da Bahia) pela oportunidade de realização deste trabalho com o acervo do Laboratório de Geologia da UESB, campus Vitória da Conquista, e pelo auxilio logístico na coleta. Ao Conselho de Desenvolvimento Científico e Tecnológico (CNPq) pelo financiamento do projeto (Universal 475291/2010-7). Aos revisores pelas significativas contribuições a este trabalho.

\section{REFERÊNCIAS}

Abranches, C.T.S. 2003. Análise e interpretação da variabilidade intra-especifica de uma população, refletida no esqueleto apendicular de Eremotherium laurillardi (Xenarthra: Megatheriidae). Programa de Pós-Graduação em Geociências, Universidade Federal do Rio de Janeiro, Dissertação de Mestrado, $64 \mathrm{p}$.

Altamirano, A.J. 2006. Los camélidos fósiles del sitio Toca da Esperança, Bahia, Brasil. Ciências Naturais, 1:147-162.

Araújo-Júnior, H.I.; Porpino, K.O.; Ximenes, C.L. \& Bergqvist, L.P. 2013. Unveiling the taphonomy of elusive natural tank deposits: a study case in the Pleistocene of northeastern Brazil. Palaeogeography, Palaeoclimatology, Palaeoecology, 378:52-74. doi:10.1016/j.palaeo.2013.04.001

Asevedo, L.; Winck, G.R.; Mothé, D. \& Avilla, L.S. 2012. Ancient diet of the Pleistocene gomphothere Notiomastodon platensis (Mammalia, Proboscidea, Gomphotheriidae) from lowland mid-latitudes of South America: stereomicrowear and tooth calculus analyses combined. Quaternary International, 255:4252. doi:10.1016/j.quaint.2011.08.037 
Auler, S.A.; Piló, L.B.; Smart, P.L.; Wang, X.; Hoffmann, D.; Richards, D.A.; Edwards, R.L.; Neves, W.A. \& Cheng, H. 2006. U-series dating and taphonomy of Quaternary vertebrates from Brazilian caves. Paleogeography, Paleoclimatology, Paleoecology, 240:508-522. doi:10.1016/j.palaeo.2006.03.002

Auler, A.S. \& Smart, P.L. 2001. Late Quaternary paleoclimate in semiarid Northeastern Brazil from U-Series dating of travertine and water-table speleothems. Quaternary Research, 55:159-167. doi:10.1006/qres.2000.2213

Barreto, E.A.S. 2010. Reconstituição da pluviosidade da Chapada Diamantina (BA) durante o Quaternário tardio através de registros isotópicos $(\mathrm{O}$ e $\mathrm{C})$ em estalagmites. Programa de Pósgraduação em Geoquímica e Geotectônica, Universidade de São Paulo, Dissertação de Mestrado, 133 p.

Beltrão, M.C. \& Locks, M. 1989. Pleistocene fauna from the "Toca da Esperança" site, (Archaeological-region of Central, Bahia, Brazil): mammals ${ }^{\circ} 1$. In: CONGRESSO BRASILEIRO DE PALEONTOLOGIA, 11, 1989. Anais, Curitiba, 685-697.

Bergqvist, L.P.; Gomide, M.; Cartelle, C. \& Capilla, R. 1997. Faunas-locais de mamíferos pleistocênicos de Itapipoca/ Ceará, Taperoá/Paraíba e Campina Grande/Paraíba. Estudo Comparativo, bioestrationômico e paleoambiental. Revista Geociências - UnG, 2:23-32.

Bertoni-Machado, C.; Scherer, C.S. \& Oliveira, T.V. 2011. Afloramento "Sítio": uma nova localidade fossilífera para o Pleistoceno da Bahia. In: CONGRESSO BRASILEIRO DE PALEONTOLOGIA, 22, 2011. Atas, Natal, p. 621-624.

Bond, M.; Madden, R.H. \& Carlini, A.A. 2006. A new specimen of Toxodontidae (Notoungulata) from the Urumaco Formation (Upper Miocene) of Venezuela. Journal of Systematic Palaeontology, 4(3):285-291. doi: 10.1017/s1477201906001854

Cartelle, C. 1980. Estudo comparativo do rádio e esqueleto da mão de Glossotherium (Ocnotherium giganteum (Lund, 1942)). Anais da Academia Brasileira de Ciências, 52:359-377.

Cartelle, C. 1992. Edentata e megamamiferos herbivoros extintos da Toca dos Ossos (Ourolândia, BA, Brasil). Programa de PósGraduação em Morfologia, Universidade Federal de Minas Gerais, Tese de Doutorado, 516 p.

Cartelle, C. 1994. Presença de Lama (Artiodactyla, Camelidae) no Pleistoceno Final - Holoceno da Bahia. Acta Geológica Leopoldensia 17:399-410.

Cartelle, C., 1999. Pleistocene Mammals of the Cerrado and Caatinga of Brazil. In: J.F. Einsenberg \& K.H. Redford (eds.) Mammals of the Neotropics. The central Tropics, University of Chicago Press, p. 7-46.

Cartelle, C. \& De Iuliis, G. 1995. Eremotherium laurillardi: the Panamerican late Pleistocene Megatheriid sloth. Journal of Vertebrate Paleontology, 15:830-841. doi:10.1080/02724634. 1995.10011265

Cartelle, C. \& De Iullis, G. 2006. Eremotherium laurillardi (Lund) (Xenarthra, Megatheriidae), the Panamerican giant ground sloth: taxonomic aspect of the ontogeny of skull and dentition. Journal of Systematic Palaeontology, 4:199-209. doi: 10.1017/ s1477201905001781

Cartelle, C. \& Lessa, G. 1988. Descrição de um novo gênero e espécie de Macraucheniidae (Mamalia, Litopterna) do Pleistoceno do Brasil. Paula-Coutiana, 3:3-26.

Cartelle, C.; De Iullis, G. \& Pujos, F. 2014. Eremotherium laurillardi (Lund, 1842) (Xenarthra, Megatheriinae) is the only valid megatheriine sloth species in the Pleistocene of intertropical Brazil: A response to Faure et al., 2014. Comptes Rendus Paleovol, 14:15-23. http://dx.doi.org/10.1016/j.crpv.2014.09.002
Dantas, M.A.T.; Dutra, R.P.; Cherkinsky, A.; Fortier, D.C.; Kamino, L.H.Y.; Cozzuol, M.A.; Ribeiro, A.S. \& Vieira, F.S. 2013b. Paleoecology and radiocarbon dating of the Pleistocene megafauna of the Brazilian Intertropical Region. Quaternary Research, 79:61-65. doi:10.1016/j.yqres.2012.09.006

Dantas, M.A.T.; Porpino, K.O.; Bauermann, S.G.; Prata, A.P.N.; Cozzuol, M.A.; Kinoshita, A.; Barbosa, J.H.O. \& Baffa, O. 2011. Megafauna do Pleistoceno superior de Sergipe, Brasil: registro taxonômico e cronológico. Revista Brasileira de Paleontologia, 14: 311-320. doi:10.4072/rbp.2011.3.10

Dantas, M.A.T.; Sanches, A.L. \& Tasso, M.A.L. 2008. Nota sobre ocorrência de fósseis da megafauna do Pleistoceno finalHoloceno de Palmas de Monte Alto, Bahia, Brasil. Revista de Geologia, 21:109-114.

Dantas, M.A.T. \& Tasso, M.A.L. 2007. Megafauna do Pleistoceno final de Vitória da Conquista, Bahia: taxonomia e aspectos tafonômicos. Scientia Plena, 3:30-36.

Dantas, M.A.T.; Xavier, M.C.T.; França, L.M.; Cozzuol, M.A.; Ribeiro, A.S.; Kinoshita, A. \& Baffa, O. 2013a. A review of the time scale and potential geographic distribution of Notiomastodon platensis (Ameghino, 1888) in the late Pleistocene of South America, Quaternary International, 317:7379. doi:10.1016/j.quaint.2013.06.031

Dantas, M.A.T. \& Zucon, M.H. 2007. Sobre ocorrência de fósseis da megafauna do Pleistoceno final de Coronel João de Sá, Bahia, Brasil. Revista Geociências - UnG, 6:191-200.

De Iuliis, G.A. 1996. Systematic review of the Megatheriinae (Mammalia: Xenarthra: Megatheriidae).University of Toronto, Doctoral Thesis, $805 \mathrm{p}$.

De Iullis, G. \& Cartelle, C. 1993. The medial carpal and metacarpal elements of Eremotherium and Megatherium (Xenarthra: Mammalia). Journal of Vertebrate Paleontology, 13:525-533. doi:10.1080/02724634.1994.10011529

Dias Neto, C.M.; Born, P.A. \& Chahud, A. 2008. Ocorrência de mamíferos extintos do Pleistoceno na localidade de Lagoa da Pedra, Município de Igaci, Alagoas. Revista Geociências - UnG, 7:110-115.

Drefahl, M. 2010. Implicações paleoambientais preliminares da análise de $\delta^{13} \mathrm{C}$ em osso de paleomastofauna procedente de Quijingue, Bahia. In: SIMPÓSIO BRASILEIRO PALEOBOTÂNICA E PALINOLOGIA, 13, 2010. Anais, Salvador, p. 239.

Fariña, R.A. \& Vizcaíno, S.F. 2001. Carved teeth and strange jaws: how glyptodonts masticated. Acta Palaeontologica Polonica, 46:219-234.

França, L.M.; Dantas, M.A.T.; Bocchiglieri, A.; Cherkinsky, A.; Ribeiro, A.S. \& Bocherens, H. 2014. Chronology and ancient feeding ecology of two upper Pleistocene megamammals from the Brazilian Intertropical Region. Quaternary Sciences Review, 99:78-83. doi:10.1016/j.quascirev.2014.04.028

França, L.M.; Asevede, L.; Dantas, M.A.T.; Bocchiglieri, A.; Avilla, L.S.; Lopes, R.P. \& Silva, J.L.L. 2015. Review of feeding ecology data of late Pleistocene mammalian herbivores from South America and discussions on niche differentiation. Earth Sciences Reviews, 140:158-165. http://dx.doi.org/10.1016/j. earscirev.2014.10.006

Goes, F.A.S.; Vieira, F.S.; Zucon, M.H.; Cartelle, C. \& Teodósio, C. 2002. Ocorrência de mamíferos pleistocênicos em Sergipe, Brasil. Arquivos do Museu Nacional, 60:199-206.

Guérin, C. \& Faure, M. 2013. Un nouveau Toxodontidae (Mammalia, Notoungulata) du Pléistocène supérieur du Nordeste du Brésil. Geodiversitas, 35:155-205. doi:10.5252/g2013n1a7 
Hubbe, A.; Vasconcelos, A.G.; Vilaboim, L.; Karmann, I. \& Neves, W. 2011. Chronological distribution of Brazilian Glyptodon sp. remains: a direct ${ }^{14} \mathrm{C}$ date for a specimen from Iporanga, São Paulo, Brazil. Radiocarbon, 53:13-19.

Kinoshita, A.; Franca, A.M.; Almeida, J.A.C.; Figueredo, A.M.; Nicolucci, P.; Graeff, C.F.O. \& Baffa, O. 2005. ESR dating at $\mathrm{K}$ and $\mathrm{X}$ band of northeastern Brazilian megafauna. Applied Radiation and Isotopes, 62:225-229. doi:10.1016/j. apradiso.2004.08.007

MacFadden, B.J. 2005. Diet and habitat of toxodont megaherbivores (Mammalia, Notoungulata) from the late Quaternary of South and Central America. Quaternary Research, 64:113-124. doi:10.1016/j.yqres.2005.05.003

MacFadden, B.J. \& Shockey, B.J. 1997. Ancient feeding ecology differentiation of Pleistocene mammalian herbivores from Tarija, Bolivia: morphological and isotopic evidence. Paleobiology, 23:77-110.

Marcolino, C.P.; Isaias, R.M.S.; Cozzuol, M.A.; Cartelle, C. \& Dantas, M.A.T. 2012. Diet of Palaeolama major (Camelidae) of Bahia, Brazil, inferred from coprolites. Quaternary International, 278:81-86. doi:10.1016/j.quaint.2012.04.002

Martinelli, A.G; Ferraz, P.F.; Cunha, G.C.; Cunha, I.C.; Carvalho, I.S.; Ribeiro, L.C.B.; Macedo-Neto, F.; Cavellani, C.L.; Teixeira, V.P.A. \& Ferraz, M.L.F. 2012. First record of Eremotherium laurillardi (Lund, 1842) (Mammalia, Xenarthra, Megatheriidae) in the Quaternary of Uberaba, Triângulo Mineiro (Minas Gerais State), Brazil. Journal of South American Earth Sciences, 37:202-207. doi:10.1016/j. jsames.2012.03.006

McDonald, H.G. 2005. Paleoecology of extinct xenarthrans and the Great American Biotic Interchange. Bulletin of the Florida Museum of Natural History, 45:313-333.

Mothé, D.; Avilla, L.S.; Cozzuol, M.A. \& Winck, G.R. 2012. Taxonomic revision of the Quaternary gomphotheres (Mammalia, Proboscidea, Gomphotheriidae) from the South American lowlands. Quaternary International, 276-277:2-7. doi:10.1016/j. quaint.2011.05.018

Oliveira, L.D.D. \& Hackspacher, P.C. 1989. Gênese e provável idade dos tanques fossilíferos de São Rafael - RN. In: CONGRESSO BRASILEIRO DE PALEONTOLOGIA, 11, 1989. Anais, Curitiba, p. 541-549.

Oliveira, L.C.; Kinoshita, A.; Barreto, A.M.F.; Figueredo, A.M.; Silva, J.L.L. \& Baffa, O. 2010. ESR dating of teeth from Brazilian megafauna. Journal of Physics, 249:1-6. doi:10.1088/1742$6596 / 249 / 1 / 012062$

Owen, R. 1838. Fossil Mammalia. In: Darwin, C. (ed.) The Zoology of the Voyage of H.M.S. Beagle, 111 p.

Paula-Couto, C. 1978. Mamíferos fósseis do Pleistoceno do Espírito Santo. Anais da Academia Brasileira de Ciências, 50:365-379.

Paula-Couto, C. 1979. Tratado de Paleomastozoologia. Rio de Janeiro, Academia Brasileira de Ciências, 590 p.

Pérez-Crespo, V.A.; Arroyo-Cabrales, J.; Alva-Valdivia, L.M.; Morales-Puentes, P. \& Cienfuegos-Alvarado, E. 2012. Diet and habitat definitions for Mexican glyptodonts from Cedral (San Luis Potosí, Mexico) based on stable isotope analysis. Geological Magazine, 149:153-157. doi:10.1017/S0016756811000951

Piló, L.B. 1998. Morfologia cárstica e materiais constituintes: dinâmica e evolução da depressão poligonal Macacos-BaúCarste de Lagoa Santa. Programa de Pós- Graduação em Geografia, Universidade de São Paulo, Tese de Doutorado, 268 p.

Porpino, K.O.; Fernicola, J.C. \& Bergqvist, L.P. 2009. A new Cingulate (Mammalia: Xenarthra), Pachymatherium brasiliense sp. nov., from the late Pleistocene of Northeastern
Brazil. Journal of Vertebrate Paleontology, 29:881-893. doi:10.1671/039.029.0305

Porpino, K.O.; Fernicola, J.C.; Cruz, L.E. \& Bergqvist, L.P. 2014. The intertropical Brazilian species of Panochthus (Xenarthra, Cingulata, Glyptodontoidea): a reappraisal of their taxonomy ans phylogentic affinities. Journal of Vertebrate Paleontology, 34:1165-1179. http://dx.doi.org/10.1080/02724634.2014.8 63203

Ribeiro, R.C.; Araújo-Júnior, H.I.; Kinoshita, A.; Figueredo, A.M.G.; Baffa, O. \& Carvalho, I.S. 2014. How much time is represented in the fossil record of tank deposits? In: SIMPÓSIO BRASILEIRO DE PALEONTOLOGIA DE VERTEBRADOS, 9, 2014. Boletim de Resumos, Vitória, p. 115.

Ribeiro, R.C. \& Carvalho, I.S. 2009. Megafauna do Quaternário tardio de Baixa Grande, Bahia, Brasil. Anuário do Instituto de Geociências, 32:42-50.

Ribeiro, R.C.; Kinoshita, A.; Figueredo, A.M.G.; Carvalho, I.S. \& Baffa, O. 2013. Electron Spin Resonance dating of the late Quaternary megafauna fossil from Baixa Grande, Bahia, Brazil. Quaternary International, 305:91-96. doi:10.1016/j. quaint.2012.07.017

Riff, D.; Avilla, L.S.; Mothé, D. \& Abranches, C.T.S. 2008. Novos registros de megafauna de mamíferos para o sertão do sudoeste baiano. Porto Alegre, Sociedade Brasileira de Paleontologia, p. 177-178 (Paleontologia em Destaque 23).

Roth, S. 1898. Catálago de los mamíferos fósiles conservados en el Museu de La Plata: Grupo Ungulata, ordem Toxodontia. Anales del Museu de La Plata, 8:33-160.

Santos, M.F.C.F.; Bergqvist, L.P.; Lima-Filho, F.P. \& Pereira, M.M.V. 2002. Feições tafonômicas observadas em fósseis pleistocênicos do Rio Grande do Norte. Revista de Geologia, 15:31-41.

Scherer, C.S. 2009. O registro fóssil dos Camelidae (Mammalia, Artiodactyla) do Pleistoceno da América do Sul. Programa de Pós-Graduação em Geociências, Universidade Federal do Rio Grande do Sul, Tese de Doutorado, 473 p.

Scherer, C.S.; Pitana, V.G. \& Ribeiro, A.M. 2009. Proterotheriidae and Macraucheniidae (Litopterna, Mammalia) from the Pleistocene of Rio Grande do Sul State, Brazil. Revista Brasileira de Paleontologia, 12(3):231-246. doi:10.4072/ rbp.2009.3.06

Schmidt, G.I. \& Ferrero, B.S. 2014. Taxonomic reinterpretation of Theosodon hystatus Cabrera and Kraglievich, 1931 (Litopterna, Macraucheniidae) and phylogenetic relationship of the family. Journal of Vertebrate Paleontology, 34:1231-1238. doi:10.108 0/02724634.2014.837393

Silva, F.M.; Filgueiras, C.F.C.; Barreto, A.M.F. \& Oliveira, E.V. 2010. Mamíferos do Pleistoceno superior de Afrânio, Pernambuco, nordeste do Brasil. Quaternary and Environmental Geosciences, 2:1-11. doi:10.5380/adequa.v2il-2.14182

Viana, M.S.S.; Silva, J.L.L.; Oliveira, P.V. \& Julião, M.S.S. 2011. Hábitos alimentares em herbívoros da megafauna Pleistocênica no nordeste do Brasil. Estudos Geológicos, 21:89-95.

Wang, X.; Auler, A.S.; Edwards, R.L.; Cheng, H.; Cristalli, P.S.; Smart, P.L.; Richards, D.A. \& Shen, C.C. 2004. Wet periods in northeastern Brazil over the past $210 \mathrm{kyr}$ linked to distant climate anomalies. Nature, 432:740-743. doi:10.1038/ nature03067

Xavier, M.C.T.; Dantas, M.A.T. \& Santana, C.C.S. 2008. A coleção de fósseis da megafauna pleistocênica do Laboratório de Arqueologia e Paleontologia da Universidade do Estado da Bahia, Senhor do Bonfim, Bahia. Porto Alegre, Sociedade Brasileira de Paleontologia, p. 13-14 (Paleontologia em Destaque 61). 
Ximenes, C.L. 2008. Tanques Fossilíferos de Itapipoca, CE Bebedouros e cemitérios de megafauna pré-histórica. In: M. Winge; C. Schobbenhaus; C.R.G. Souza; A.C.S. Fernandes; M. Berbert-Born \& E.T. Queiroz (eds.) Sitios Geológicos e Paleontológicos do Brasil, DNPM, CPRM, p. 1-13.

Zurita, A.E.; Oliveira, E.V.; Toriño, P.; Rodriguez-Bualó, S.M.; Scillato-Yané, G.J.; Luna, C. \& Krapovickas, J. 2011. On the taxonomic status of some Glyptodontidae (Mammalia, Xenarthra, Cingulata) from the Pleistocene of South America. Annales de Paléontologie, 97:63-83. doi:10.1016/j.annpal.2011.07.003

Received in April, 2014; accepted in March, 2015. 